\title{
In ovo evaluation of antiviral effects of aqueous garlic (Allium sativum) extract against a velogenic strain of Newcastle disease virus
}

\author{
Fatemeh Doostmohammadian' $^{1}$, Tahoora Shomali ${ }^{1 *}$, Najmeh Mosleh $^{2} \mathbb{D}$, Mitra Mohammadi $^{(\mathbb{D}}$ \\ ${ }^{1}$ Division of Pharmacology and Toxicology, Department of Basic Sciences, School of Veterinary Medicine, Shiraz University, Shiraz, Iran \\ ${ }^{2}$ Department of Clinical Sciences, School of Veterinary Medicine, Shiraz University, Shiraz, Iran
}

\section{A R T I C L E I N F O}

Article Type:

Original Article

\section{Article History:}

Received: 10 August 2019

Accepted: 29 October 2019

\section{Keywords:}

Newcastle disease

Garlic

Lethal dose 50

Viral load

\begin{abstract}
A B S T R A C T
Introduction: The antiviral property of aqueous garlic extract against a virulent velogenic field isolate of Newcastle disease virus (NDV) was investigated in a time of addition assay in embryonated chicken eggs (ECEs).

Methods: The ECEs were inoculated with the lowest concentration of the virus with HA (haemagglutination) positive activity. After determination of extract toxicity in ECEs, administration of different concentrations of the extract $(0.5,1,2,4 \mathrm{mg} / \mathrm{mL})$ or ribavirin (comparative control) was performed 8 hours before (pretreatment), simultaneously (cotreatment) or 8 hours after (post treatment) virus injection. Allantoic fluids were harvested for infectivity determination, transmission electron microscopy (TEM) and viral load (HA titer) assay. In vitro HA blocking activity test was also performed.

Results: Allicin content of the extract was $16.6 \%$ by HPLC method. The best viability results were related to the extract in pretreatment and ribavirin in co-treatment trials $(\mathrm{p}<0.05$ as compared to infected ECEs with no treatment). Pre and co-treatment assays showed better results on HA titer of garlic treated groups. In infectivity assay, the $50 \%$ embryo lethal dose $\left(E_{50}\right)$ values of NDV were roughly 500 and 50 folds of $\mathrm{ELD}_{50}$ of the untreated virus in pre and co-treatment, respectively. No change was observed in viral shapes in TEM analysis nor HA blocking activity in vitro.

Conclusion: Aqueous extract of garlic shows antiviral effects against a velogenic strain of NDV in ovo accompanied by a reduction in virus infectivity and titer. These effects are most pronounced in pretreatment trial.
\end{abstract}

Implication for health policy/practice/research/medical education:

This study shows the antiviral effects of aqueous extract of garlic against a velogenic field strain of Newcastle disease virus which may be important as a base for the future studies on the potential of garlic extract for preventing this viral disease in poultry industry.

Please cite this paper as: Doostmohammadian F, Shomali T, Mosleh N, Mohammadi M. In Ovo evaluation of antiviral effects of aqueous garlic (Allium sativum) extract against a velogenic strain of Newcastle disease virus. J Herbmed Pharmacol. 2020;9(3):232-238. doi: 10.34172/jhp.2020.30.

\section{Introduction}

Viral diseases are among the most serious, devastating and afflicting threats to poultry industry and result in constant huge loss around the world. Unfortunately, fighting against viruses is not easy. This has led to an urgent need for finding new compounds with novel mechanisms, relatively safe profile (both from human and animal aspects) and of course cost-effectiveness.

Newcastle disease (ND), as an infectious disease in avian species, is the fourth most problematic disease for poultry industry with worldwide distribution (1). The causative agent of the disease is Newcastle disease virus (NDV) or avian avulavirus which is a single stranded RNA virus from paramyxoviridae family (2). This virus has three distinct pathotypes based on mean death time in chicken embryos including velogenic (40-60 hours), mesogenic (60-90 hours) and lentogenic (90-150 hours) strains (3). Despite frequent use of live and killed commercial vaccines and 
intensive vaccination programs, especially in the endemic regions of the world, high number of outbreaks is reported annually which imposes huge economic burden on poultry producers (1).

Antiviral drugs are not ordinarily used in poultry industry due to high toxicity, high costs and legislative limitations with regard to drug residues in poultry products and emergence of resistant strains. Finding medicinal plants or natural compounds with antiviral properties as an alternative approach or at least in combination with other preventive programs against poultry viral diseases is an ongoing and highly demanded process. Different plants have been assayed for their antiviral effects against NDV including sweet wormwood (Artemisia annua L.) (4), Commiphora swynnertonii (5), Achillea millefolium, Thymus vulgaris (6) and Glycyrrhiza glabra (7) extracts.

Garlic (Allium sativum), which is widely grown for its distinctive taste, is one of the most important medicinal herbs used against various diseases. Garlic is a species in onion genus belonging to the Liliaceae family (8). Garlic contains a variety of bioactive compounds including flavonoids and sulfur-containing compounds with potent medicinal properties. Some bioactive compounds in garlic can prevent formation of free radicals, cancer, cardiovascular and neuronal degeneration diseases. Antidiabetic, anticancer, anti-inflammatory, antioxidant, antithrombotic, antihypertensive as well as antimicrobial activities of garlic are the most known medicinal properties of this plant $(9,10)$.

It is believed that the antimicrobial activities of garlic are primarily based on allicin. Allicin (2-propenylthiosulphinate) is the most predominant garlic's thiosulfinate compound. The aqueous extracts of garlic are particularly rich in allicin. The enzyme alliinase converts alliin into allicin which is responsible for the pungent smell in crushed fresh garlic (9).

Garlic has a profound niche in both human and veterinary traditional medicine and there are oral reports of its use for prevention and treatment of ND in folk medicine.

Among modern pharmacological studies, there are a few reports on the antiviral activity of garlic extract against different viruses. The antiviral activities of garlic extract and its different compounds against herpes simplex virus type 1 , herpes simplex virus type 2, parainfluenza virus type 3, vaccinia virus, vesicular stomatitis virus, and human rhinovirus type 2 have been shown in vitro (11). Mohajer Shojai et al reported the inhibitory effects of garlic extract against 4/91 and M41 strains of infectious bronchitis virus (IBV) in ovo (12). Based on the limited knowledge about the antiviral properties of garlic extract against NDV, this research investigated the antiviral effect of aqueous extract of garlic against this virus in a time of addition assay in embryonated chicken eggs (ECEs) which serve as the borderline of in vitro and in vivo experiments.

\section{Materials and Methods}

Preparation of garlic aqueous extract

Garlic cloves were purchased from a local market and authenticated by a botanist. Garlic cloves were squashed in sterile distilled water $(4 \mathrm{~g} / 20 \mathrm{~mL})$. After 24 hours it was centrifuged twice at $3400 \mathrm{~g}$ (10 minutes). Then the supernatant was filtered by using a $0.22 \mu \mathrm{m}$ membrane filter. After solvent evaporation at $40^{\circ} \mathrm{C}$, the extract was poured into a small glass container and stored at $-70^{\circ} \mathrm{C}$. The method of extraction was based on the study by Velliyagounder et al (13). The extract yield was $14.8 \%$. Sterile phosphate-buffered saline (PBS) containing penicillin-streptomycin (3000 unit penicillin+3000 mg streptomycin in $1 \mathrm{ml}$ of solvent) was used as the solvent of extract in all experiments. Phytochemical analysis of garlic extract was also performed for determination of allicin content by using HPLC method as described previously $(14,15)$.

\section{Embryonated chicken eggs}

The specific antibody negative (against NDV) ECEs were used in all the experiments. The 9 to 10 -day-old embryos at the time of inoculation were used. Death of embryos which died within 24 hours after infection was considered nonspecific and replaced with new ECEs.

\section{Toxicity assay of garlic extract in ECEs}

To determine maximum non-toxic concentration (MNTC) of garlic extract in ECEs, the extract was diluted to the desired concentrations of $0.03,0.06,0.125,0.25,0.5$, $1,2,4,8,16,32,64$ and $128 \mathrm{mg} / \mathrm{mL}$. Then $0.1 \mathrm{~mL}$ of each extract dilution was inoculated into allantoic cavity of five ECEs, incubated for 72 hours and monitored daily. Five ECEs were also considered as negative control and injected only with $0.1 \mathrm{~mL}$ of solvent. The highest concentration that was not associated with any death after $72 \mathrm{~h}$ was considered as MNTC ( $4 \mathrm{mg} / \mathrm{mL})$. This concentration as well as three concentrations lower than that $(2,1$ and 0.5 $\mathrm{mg} / \mathrm{mL}$ ) (totally 4 concentrations) were selected for later experiments.

\section{Virus characteristics}

A virulent field isolate of NDV (Gene Bank accession number: JF820294.1), was used as the virus stock. The virus was propagated in ECEs by inoculating the virus via the allantoic route.

To determine the appropriate dilution of the virus for inoculation to ECEs in the experiments, serial dilutions were made from the virus stock and $100 \mu \mathrm{L}$ of each dilution was injected to allantoic cavity of five, 9 to 10 day old-ECEs following the procedure outlined by World Organization for Animal Health (OIE) (2012) manual (16). Due to highly pathogenic and fatal nature of the virus, the lowest concentration of the virus with haemagglutination (HA) positive activity in infected embryos $\left(2.5 \times 10^{-10}\right)$ was 
considered for inoculation of ECEs in all experiments. Rapid HA assay (spot HA test) was used to determine HA positive samples (17).

Antiviral assay (Time of addition assay)

Antiviral efficacy of aqueous garlic extract was evaluated by time of addition study consisted of pre, post and cotreatment of virus infected ECEs with garlic extract. Each trial was performed on thirty five, 9 to 10 day-old ECEs randomly divided into 7 (A-G) equal groups (5 eggs each) as follows: A-F groups were aseptically infected by allantoic route inoculation of $0.1 \mathrm{ml}$ of $2.5 \times 10^{-10}$ dilution of the virus, while $\mathrm{G}$ group received antibiotic-contained PBS (Negative control). A-D groups also received $0.1 \mathrm{~mL}$ of garlic extract at $0.5,1,2$ and $4 \mathrm{mg} / \mathrm{mL}$ concentrations, respectively while group $\mathrm{E}$ was treated with $0.1 \mathrm{ml}$ ribavirin (Sigma, USA; $1.25 \mu \mathrm{g} / 0.1 \mathrm{~mL}$ ) (18) as comparative control. G and F groups were injected again with $0.1 \mathrm{ml}$ of antibiotic-contained PBS and served as negative control and positive or virus control, respectively. All drugs were administered via allantoic injection.

Administration of garlic extract or ribavirin was performed 8 hours before (pretreatment), simultaneously or 8 hours after (post treatment) virus injection in each trial.

After last injection, all eggs were incubated for 72 hours at $37^{\circ} \mathrm{C}$ and egg candling was performed every 24 hours for evaluation of embryonic viability during the incubation period based on embryonic movements and appearance of blood vessels. Time of death was recorded for each case. Deaths before 24 hours were omitted and replaced. Then, the eggs were placed in refrigerator for chilling at $4^{\circ} \mathrm{C}$, overnight. The allantoic fluid was harvested from all groups and the presence of the virus in individual samples was tested by rapid HA assay. HA titer of the NDV was assessed in pooled samples of each group by HA test using $1 \%$ RBC suspension (17). All procedures used in this study were in accordance with our institutional ethical guidelines for use of animals in experiments.

Determination of virus infectivity in harvested allantoic samples

To measure the concentration of infectious NDV in harvested allantoic fluids of different trials, 50 percent Embryo Lethal Dose $\left(\mathrm{ELD}_{50}\right)$ of pooled allantoic samples obtained from the garlic treated groups that showed best response based on rapid HA and viability results or positive control were determined (17). Briefly ten-fold serial dilutions of the test allantoic fluids were made and each dilution was injected into five ECEs. After incubation, the results were used to determine $\mathrm{ELD}_{50}$ by Reed and Muench formula (19).

Electron microscopy

In addition to infectivity determination, fresh pooled samples of harvested allantoic fluids from negative and positive controls as well as ribavirin or garlic treated groups of all 3 trials with best above mentioned results were sent for transmission electron microscopy (TEM) analysis using a Philips CM10 TEM at $100 \mathrm{kV}$ by negative staining.

In vitro determination of virus HA block

Four HA units (HAU) of viruses were used for hemagglutination-inhibition (HI) test (17). After incubating virus with different concentrations of garlic extract $(0.25,0.5,1,2,4,8$ and $16 \mathrm{mg} / \mathrm{mL}$ in sterile PBS) in $1: 1 \mathrm{v} / \mathrm{v}$ ratio for 1 hour at room temperature, HI test was performed in round-bottomed 96-well micro-plates, using $1 \%$ chicken RBC. Virus without garlic extract as well as different concentrations of garlic extract without virus were used as controls. Each test was performed in pentaplicate. The method was borrowed from Chen et al (20) with some modifications.

Statistical analysis

For comparing embryo viability among different groups, Fisher's exact test was used with $\mathrm{p}<0.05$ as significant level, using SPSS software version 22 .

\section{Results}

Allicin content of the extract

As previously stated, allicin content of the garlic aqueous extract was determined by HPLC method. The allicin content of the extract was $16.6 \%$.

Viability and rapid HA results in time of addition assays Results related to viability of embryos and HA rapid test of allantoic fluid of different groups in 3 trials are summarized in Tables 1 (pre-treatment), 2 (co-treatment) and 3 (post-treatment trial).

In all 3 trials, $100 \%$ of embryos in positive control group (F) died after 48 hours incubation and all allantoic fluid samples were positive in rapid HA test while no death was observed in negative control (G group), and all allantoic fluid samples remained HA negative. All embryos in all groups and trials were alive at 24 hours post-incubation (inclusion criterion).

In all 3 trials no significant difference was observed in the number of live embryos among different groups after 48 hours of incubation $(P>0.05)$. However, after 72 hours of incubation, in pretreatment trial, garlic treated groups (except of D group) showed significantly higher viability as compared to positive control group $(P<0.05)$, where all garlic treated groups showed statistically the same results $(P>0.05)$. Ribavirin administration was not associated with a significant reduction in number of dead embryos as compared to positive control group $(P>0.05)$.

In co-treatment trial, all embryos of garlic treated and positive control groups died after 72 hours incubation, 
Table 1. Number of live embryo at different time post incubation $(24,48$ and $72 \mathrm{~h}$ ) and number of haemagglutination (HA) rapid positive allantoic fluid samples at $72 \mathrm{~h}$ post-incubation in pre-treatment trial $(n=5)$

\begin{tabular}{llllllll}
\hline & & A & B & C & D & E & F \\
\hline \multirow{3}{*}{ No. of live embryos } & $24 \mathrm{~h}$ & 5 & 5 & 5 & 5 & 5 & 5 \\
\cline { 2 - 7 } & $48 \mathrm{~h}$ & 5 & 4 & 5 & 5 & 5 & 5 \\
\hline \multirow{2}{*}{ No. of rapid HA positive samples } & 1 & $4^{*}$ & 0 & $4^{*}$ & 3 & 3 & 5 \\
\hline
\end{tabular}

A-E: groups that received $0.1 \mathrm{~mL}$ of garlic extract at $0.5,1,2$ and $4 \mathrm{mg} / \mathrm{mL}$ concentrations or ribavirin $(1.25 \mu \mathrm{g}) 8 \mathrm{~h}$ prior to inoculation of $0.1 \mathrm{ml}$ of Newcastle disease virus (NDV); F and G groups were considered as positive and negative controls, respectively.

*Significantly different with positive control $(\mathrm{F})$ group $(P<0.05)$.

Table 2. Number of viable embryo at different time post incubation (24, 48 and $72 \mathrm{~h}$ ) and number of haemagglutination (HA) rapid positive allantoic fluid samples at $72 \mathrm{~h}$ post incubation in co-treatment trial $(\mathrm{n}=5)$

\begin{tabular}{|c|c|c|c|c|c|c|c|c|}
\hline & & A & B & C & D & $\mathbf{E}$ & $\mathbf{F}$ & G \\
\hline \multirow{3}{*}{ No. of live embryos } & $24 \mathrm{~h}$ & 5 & 5 & 5 & 5 & 5 & 5 & 5 \\
\hline & $48 \mathrm{~h}$ & 5 & 5 & 5 & 5 & 5 & 5 & 5 \\
\hline & $72 \mathrm{~h}$ & 0 & 0 & 0 & 0 & $5 *$ & 0 & 5 \\
\hline \multicolumn{2}{|c|}{ No. of rapid HA positive samples } & 5 & 5 & 5 & 5 & 0 & 5 & 0 \\
\hline
\end{tabular}

A-E: groups that received $0.1 \mathrm{ml}$ of garlic extract at $0.5,1,2$ and $4 \mathrm{mg} / \mathrm{mL}$ concentrations or ribavirin $(1.25 \mu \mathrm{g}) 8 \mathrm{~h}$ prior to inoculation of $0.1 \mathrm{ml}$ of Newcastle disease virus (NDV); F and G groups were considered as positive and negative controls, respectively.

*Significantly different with positive control $(\mathrm{F})$ group $(P<0.05)$.

Table 3. Number of viable embryo at different time post incubation (24, 48 and $72 \mathrm{~h})$ and number of haemagglutination (HA) rapid positive allantoic fluid samples at $72 \mathrm{~h}$ post incubation in post-treatment trial $(n=5)$

\begin{tabular}{|c|c|c|c|c|c|c|c|c|}
\hline & & A & B & C & D & E & $\mathbf{F}$ & G \\
\hline \multirow{3}{*}{ No. of live embryos } & $24 \mathrm{~h}$ & 5 & 5 & 5 & 5 & 5 & 5 & 5 \\
\hline & $48 \mathrm{~h}$ & 5 & 3 & 3 & 4 & 5 & 5 & 5 \\
\hline & $72 \mathrm{~h}$ & 0 & 0 & 0 & 1 & 3 & 0 & 5 \\
\hline \multicolumn{2}{|c|}{ No. of rapid HA positive samples } & 5 & 5 & 5 & 5 & 5 & 5 & 0 \\
\hline
\end{tabular}

A-E: groups that received $0.1 \mathrm{~mL}$ of garlic extract at $0.5,1,2$ and $4 \mathrm{mg} / \mathrm{mL}$ concentrations or ribavirin $(1.25 \mu \mathrm{g}) 8 \mathrm{~h}$ prior to inoculation of $0.1 \mathrm{ml}$ of Newcastle disease virus (NDV); F and G groups were considered as positive and negative controls, respectively.

ribavirin administration resulted in $100 \%$ survival of embryos ( $P<0.05$ as compared to $\mathrm{F}$ group).

In post treatment trial after 72 hours of incubation neither ribavirin nor different concentrations of the extract could significantly affect viability as compared to F group $(P>0.05)$.

HA titer results in time of addition assays

Table 4 summarizes HA titers of pooled samples from different groups in 3 trials. Pre- and co-treatment assays

Table 4. Haemagglutination (HA) titers of NDV in pooled allantoic fluid samples of different groups in 3 trials

\begin{tabular}{llllllll}
\hline & A & B & C & D & E & F & G \\
\hline Pretreatment & 8 & 7 & 8 & 10 & 5 & 11 & 1 \\
Co-treatment & 11 & 10 & 7 & 7 & 1 & 11 & 1 \\
Post treatment & 10 & 9 & 9 & 8 & 7 & 11 & 1 \\
\hline
\end{tabular}

A-E: groups that received $0.1 \mathrm{~mL}$ of garlic extract at $0.5,1,2$ and $4 \mathrm{mg} /$ $\mathrm{mL}$ concentrations or ribavirin $(1.25 \mu \mathrm{g}) 8 \mathrm{~h}$ prior to inoculation of 0.1 $\mathrm{ml}$ of Newcastle disease virus (NDV); F and G groups were considered as positive and negative controls, respectively. showed better results on HA titer of garlic treated groups.

$E L D_{50}$ of harvested allantoic samples in trials

As previously stated $E L D_{50}$ of NDV in allantoic fluids of pooled samples of garlic treated embryos from selected groups $(1 \mathrm{mg} / \mathrm{kg}$ in pretreatment, $2 \mathrm{mg} / \mathrm{kg}$ in co-treatment and $4 \mathrm{mg} / \mathrm{mL}$ in post treatment) in different trials was determined. The $E L D_{50}$ value of NDV determined as $10^{-}$ 7.42 in pretreatment and $10^{-8.48}$ in co-treatment trials (vs. $2 \times 10^{-10.42}$ of untreated virus in positive control) which were roughly 500 and 50 folds higher than the $E L D_{50}$ of the untreated virus. For post treatment, results of $E L D_{50}$ determination was around that of untreated virus.

Morphology of virus in TEM

In all groups viral particles were observed mostly in spherical shape. No change was observed in virus shape or the appearance of surface glycoproteins in different groups (Figure 1A-G).

In vitro HA block

In vitro Incubation of NDV with different concentrations 

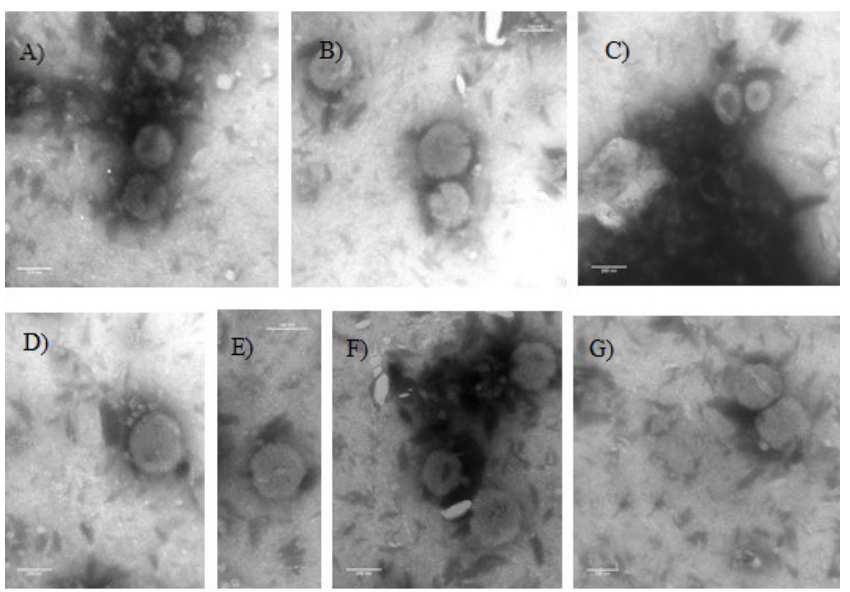

Figure 1. Representative transmission electron micrographs of NDV in harvested allantoic fluids from embryos in different groups. A-C: pre, co and post treatments with garlic extracts; D-F: pre-, co- and post-treatments with ribavirin; G: Virus control (no treatment).

of garlic extract did not show HA blocking activity of the extract as shown by obvious HA in these samples.

\section{Discussion}

In the present study we evaluated the antiviral activity of aqueous extract of garlic against a velogenic strain of NDV based on the viability of embryos in a time of addition assay in in ovo conditions. We observed that administration of the extract in pretreatment assay was more effective in reducing embryonic death than co-treatment or post treatment while ribavirin showed the best result in cotreatment assay. Time of addition assays are important in determining the step of virus life cycle which is affected by antiviral agents and therefore are beneficial in illustration of mechanism of action of antiviral compounds. Pretreatment assay majorly determines two mechanisms of antiviral effects: the acceleration of antiviral host immune factors e.g. interferon production and/or the ability of the drug to block virus attachment to host cells (21).

In a study by Schilling et al (22), the authors characterized the transcriptional response of selected innate immune genes to NDV infection in chicken embryos at days 10 , 14 and 18 of embryonic development and they suggested that the innate immune response after 72 hours of viral challenge was consistent in 18-day chicken embryo. Regarding the ages of the chicken embryos, used in the present study (9-10 days old), the chance that antiviral effect of garlic could be mediate by immunostimulation might be excluded.

Hemagglutinin-neuraminidase is a viral glycoprotein of NDV and acts as a decisive factor for virus attachment to host cells. This protein has a role in multiple viral functions including binding to receptor (sialic acid) for virus attachment to cells, receptor destroying (neuraminidase) activity for virus budding, and fusion protein activation (23). In the present study we evaluated the HA blocking activity of garlic extract in vitro and we observed no blocking activity. Moreover, TEM images did not show a considerable change in structure or shape of surface hemagglutinin-neuraminidase glycoproteins. Therefore, it seems that inhibition of viral attachment to cells through affecting HA is not involved in the antiviral effect of garlic extract that was observed in pretreatment assay.

It has been demonstrated that NDV may enter host cells through endocytosis and its entry is dependent to protein kinase C (PKC) activation (24). Moreover, NDV infectivity is impaired by inhibition of PKC (25). As previously stated, we observed a 500 -fold decrease in $\mathrm{ELD}_{50}$ of virus in pretreatment assay. In a mammalian model it has been demonstrated that allicin, as the main constituent of garlic, has inhibitory effects on PKC activity (26). Therefore, PKC inhibition by garlic extract may be involved in reducing infectivity of NDV and antiviral effect of garlic extract as observed in pretreatment assay, although this hypothesis needs to be approved in further studies.

In the present study, post treatment with garlic extract was not associated with considerable effects. Newcastle disease viruses have the most rapid replication cycle among all paramyxoviruses. For instance, attachment is almost complete in 10 minutes, viral protein synthesis is implemented within 6 hours post-infection and the maximal yield of viruses is achieved within 12 hours postinfection (27). We administered garlic extract 8 hours post-infection when virus replication had considerably progressed. This may explain the lack of considerable effect of garlic on NDV in post-treatment assay.

Another finding of our study was the change in virus HA titers of garlic treated groups which was again more profound in pre- and co-treatments. Therefore, garlic may have affected the replication of virus with resultant decreases in the number of viral particles. It must be kept in mind that HA test does not discriminate between intact and degraded viral particles (17). Regarding the lack of 
effect on viability of embryos in post treatment trial, the virucidal effects of the extract are not quite expected.

\section{Conclusion}

Aqueous extract of garlic shows antiviral effects against a velogenic strain of NDV in ovo accompanied by a reduction in virus infectivity and titer. These effects are most pronounced in pretreatment trial and are more probably due to diminished virus attachment and entry in a host-related manner.

\section{Authors' contributions}

All authors have contributed significantly as follows: TS and NM substantial contributions to the conception and design of the work, interpretation of data and drafting the work; FD and MM data acquisition and analysis. All authors read and confirmed the final version for publication.

\section{Conflict of interests}

Authors have no conflict of interest.

\section{Ethical considerations}

All procedures used in this study were in accordance with our institutional ethical guidelines (Shiraz University, School of Veterinary Medicine) which are compatible with Directive 2010/63/EU for use of animals in experiments (INT1M163773).

\section{Funding/Support}

The study was funded by Shiraz University, School of Veterinaru Medicine according to grant number: 95 INT1M163773.

\section{References}

1. Dimitrov KM, Afonso CL, Yu Q, Miller PJ. Newcastle disease vaccines-A solved problem or a continuous challenge? Vet Microbiol. 2017;206:126-36. doi: 10.1016/j. vetmic.2016.12.019

2. He Y, Taylor TL, Dimitrov KM, Butt SL, Stanton JB, Goraichuk IV, et al. Whole-genome sequencing of genotype VI Newcastle disease viruses from formalin-fixed paraffinembedded tissues from wild pigeons reveals continuous evolution and previously unrecognized genetic diversity in the U.S. Virol J. 2018;15(1):9. doi: 10.1186/s12985-0170914-2.

3. Swayne DE, Glisson JR, McDougald LR, Nolan LK, Suarez DL, Nair VL. Diseases of Poultry. Ames: John Wiley \& Sons; 2013.

4. Liu Y, Yan G, Chen G, Zhang J. Efficacy trials of crude extraction from Artemisia annua L. against Newcastle disease virus in vivo in Xinjiang. Mod Appl Sci. 2009;3(5):176-8. doi: 10.5539/mas.v3n5p176.

5. Bakari GG, Max RA, Mdegela RH, Phiri EC, Mtambo MM. Antiviral activity of crude extracts from Commiphora swynnertonii against Newcastle disease virus in ovo. Trop Anim Health Prod. 2012;44(7):1389-93. doi: 10.1007/ s11250-012-0076-6.

6. Rezatofighi SE, Seydabadi A, Seyyed Nejad SM. Evaluating the efficacy of Achillea millefolium and Thymus vulgaris extracts against Newcastle disease virus in Ovo. Jundishapur J Microbiol. 2014;7(2):e9016. doi: 10.5812/jjm.9016.

7. Omer MO, Almalki WH, Shahid I, Khuram S, Altaf I, Imran S. Comparative study to evaluate the anti-viral efficacy of Glycyrrhiza glabra extract and ribavirin against the Newcastle disease virus. Pharmacognosy Res. 2014;6(1):611. doi: 10.4103/0974-8490.122911.

8. Iciek M, Kwiecień I, Włodek L. Biological properties of garlic and garlic-derived organosulfur compounds. Environ Mol Mutagen. 2009;50(3):247-65. doi: 10.1002/em.20474.

9. Yadav S, Trivedi NA, Bhatt JD. Antimicrobial activity of fresh garlic juice: an in vitro study. Ayu. 2015;36(2):203-7. doi: 10.4103/0974-8520.175548.

10. Putnik P, Gabrić D, Roohinejad S, Barba FJ, Granato $\mathrm{D}$, Mallikarjunan $\mathrm{K}$, et al. An overview of organosulfur compounds from Allium spp.: from processing and preservation to evaluation of their bioavailability, antimicrobial, and anti-inflammatory properties. Food Chem. 2019;276:680-91. doi: 10.1016/j. foodchem.2018.10.068.

11. 16. Weber ND, Andersen DO, North JA, Murray BK, Lawson LD, Hughes BG. In vitro virucidal effects of Allium sativum (garlic) extract and compounds. Planta Med. 1992;58(5):417-23. doi: 10.1055/s-2006-961504.

12. Mohajer Shojai T, Ghalyanchi Langeroudi A, Karimi V, Barin A, Sadri N. The effect of Allium sativum (garlic) extract on infectious bronchitis virus in specific pathogen free embryonic egg. Avicenna J Phytomed. 2016;6(4):458267.

13. Velliyagounder K, Ganeshnarayan K, Velusamy SK, Fine DH. In vitro efficacy of diallyl sulfides against the periodontopathogen Aggregatibacter actinomycetemcomitans. Antimicrob Agents Chemother. 2012;56(5):2397-407. doi: 10.1128/aac.00020-12.

14. Arzanlou M, Bohlooli S. Introducing of green garlic plant as a new source of allicin. Food Chem. 2010;120(1):179-83. doi: 10.1016/j.foodchem.2009.10.004.

15. Arzanlou M, Bohlooli S, Ranjbar Omid M. Purification of allicin from garlic extract using semi-preparative high performance liquid chromatography. Jundishapur J Nat Pharm Prod. 2015;10(2):e17424. doi: 10.17795/jjnpp-17424.

16. World Organization for Animal Health (OIE). Chapter 2.3.14. Newcastle disease. In: Manual of Diagnostic Tests and Vaccines for Terrestrial Animals. Paris: OIE; 2012. p. 1-19.

17. Grimes SE. A Basic Laboratory Manual for the Small-Scale Production and Testing of I-2 Newcastle Disease Vaccine. RAP Publication, FAO-APHCA; 2002.

18. Azeem S, Ashraf M, Rasheed MA, Anjum AA, Hameed R. Evaluation of cytotoxicity and antiviral activity of ivermectin against Newcastle disease virus. Pak J Pharm Sci. 2015;28(2):597-602.

19. Reed LJ, Muench H. A simple method of estimating fifty per cent endpoints. Am J Epidemiol. 1938;27(3):493-7. doi: 10.1093/oxfordjournals.aje.a118408.

20. Chen TY, Chen DY, Wen HW, Ou JL, Chiou SS, Chen JM, et al. Inhibition of enveloped viruses infectivity by curcumin. 
PLoS One. 2013;8(5):e62482. doi: 10.1371/journal. pone.0062482.

21. Aoki-Utsubo C, Chen M, Hotta H. Time-of-addition and temperature-shift assays to determine particular step(s) in the viral life cycle that is blocked by antiviral substance(s). Bio Protoc. 2018;8(9):e2830. doi: 10.21769/BioProtoc.2830

22. Schilling MA, Katani R, Memari S, Cavanaugh M, Buza J, Radzio-Basu J, et al. Transcriptional innate immune response of the developing chicken embryo to Newcastle disease virus infection. Front Genet. 2018;9:61. doi: 10.3389/fgene.2018.00061.

23. Yuan P, Swanson KA, Leser GP, Paterson RG, Lamb RA, Jardetzky TS. Structure of the Newcastle disease virus hemagglutinin-neuraminidase $(\mathrm{HN})$ ectodomain reveals a four-helix bundle stalk. Proc Natl Acad Sci U S A. 2011;108(36):14920-5. doi: 10.1073/pnas.1111691108.

24. Tan L, Zhang Y, Zhan Y, Yuan Y, Sun Y, Qiu X, et al.
Newcastle disease virus employs macropinocytosis and Rab5a-dependent intracellular trafficking to infect DF-1 cells. Oncotarget. 2016;7(52):86117-33. doi: 10.18632/ oncotarget.13345.

25. Sánchez-Felipe L, Villar E, Muñoz-Barroso I. Entry of Newcastle disease virus into the host cell: role of acidic $\mathrm{pH}$ and endocytosis. Biochim Biophys Acta. 2014;1838(1 Pt B):300-9. doi: 10.1016/j.bbamem.2013.08.008.

26. Lu CW, Hung CF, Lin TY, Hsieh TY, Wang SJ. Allicin inhibits glutamate release from rat cerebral cortex nerve terminals through suppressing $\mathrm{Ca}(2+)$ influx and protein kinase C activity. J Med Food. 2019;22(7):696-702. doi: 10.1089/jmf.2018.4337.

27. Peeples ME. Newcastle disease virus replication. In: Alexander DJ, ed. Newcastle Disease. Developments in Veterinary Virology, vol 8. Boston, MA: Springer; 1998. 